Cumhuriyet University

Journal of Economics and Administrative Sciences

E-ISSN: 2687-4032

2022, 23(1), pp.317-336.

Doi: 10.37880/cumuiibf.1013654

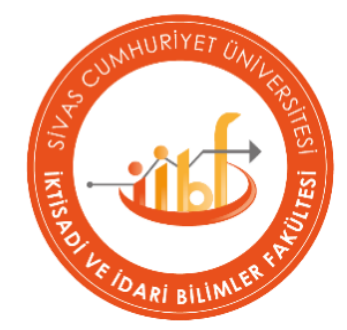

\title{
THE EFFECT OF USING ROBOT WAITERS IN RESTAURANTS ON CONSUMERS' BEHAVIORAL INTENTIONS
}

\begin{abstract}
This study examines the effect of using robot waiters in restaurants on consumers' behavioral intentions. To achieve this aim, data were collected from 385 people using online questionnaire and experiment method. The data were analyzed using the SPSS 25 program. According to the one-sample t-test result; using robot waiters is not a significant predictor of consumers' intentions to use robotic restaurants. In addition, based on the independent samples t-test results; between female and male, and also the results of ANOVA for independent groups; between $X, Y$, and $Z$ generations, there is no significant difference in consumers' intention to use robotic restaurants. It was concluded the perceived innovativeness of using robotic restaurants, the perceived value, perceived enjoyment, and attractiveness of using robot waiters, are positive and important predictors of attitude towards using robotic restaurants. In addition, the attitude towards using the robotic restaurant is a positive and important predictor of both the intention to use the robotic restaurants and the willingness to pay more to use the robotic restaurants. At the end of the study, suggestions were made within the framework of limitations.
\end{abstract}

Article History:

Date submitted:

22 October 2021

Date accepted:

23 December 2021

Jel Codes:

M30, M31

Keywords:

Robot Waiters,

Robotic Restaurants,

Behavioral Intentions

Suggested Citation: Çelik, Z. \& Aydın, İ. (2022). The Effect of Using Robot Waiters in Restaurants on Consumers' Behavioral Intentions. Cumhuriyet University Journal of Economics and Administrative Sciences, 23(1), 317-336.

${ }^{1}$ Res. Asst. Dr., Van Yüzüncü Y1l University, Erciş Faculty of Business, Department of Business Administration, zubeyircelik@yyu.edu.tr, ORCID ID: 0000-0003-1692-9378

${ }^{2}$ Asst. Prof. Dr., Van Yüzüncü Yıl University, Erciş Faculty of Business, Department of Business Administration, ibrahimaydin@yyu.edu.tr, ORCID ID: 0000-0002-0720-364X 


\section{RESTORANLARDA ROBOT GARSONLAR KULLANMANIN TÜKETICILERIN DAVRANIŞSAL NIYYETLERINE ETKISII}

\section{Zübeyir ÇELÍK ${ }^{1}$ \\ İbrahim AYDIN ${ }^{2}$}

$\ddot{O} z$

Bu çalışma, restoranlarda robot garsonlar kullanmanın tüketicilerin davranışsal niyetleri üzerindeki etkisini incelemektedir. Bu amaçla online anket ve deney yöntemi kullanılarak 385 kişiden veri toplanmıştır. Veriler SPSS 25 paket programı kullanılarak analiz edilmiştir. Tek örneklem t-testi sonucuna göre; robot garsonların kullanılması, tüketicilerin robotik restoranları kullanma niyetlerinin önemli bir yordayıcısı değildir. Buna ek olarak, bağımsız örneklemler t-testi sonuçlarına göre; kadınlar ve erkekler arasında ve ayrıca bağımsız gruplar için ANOVA sonuçlarına göre; X, Y ve Z jenerasyonları arasında tüketicilerin robotik restoranlarl kullanma niyetlerinde anlaml bir farklllik yoktur. Bununla birlikte, basit lineer regresyon analizi ile elde edilen sonuçlara göre; robotik restoran kullanmanın algılanan yenilikçiliği ve robot garsonlar kullanmanın algılanan değeri, algılanan zevki ve çekiciliği, robotik restoran kullanımına yönelik tutumun olumlu ve önemli yordayıcılarıdır. Ayrıca robotik restoran kullanımına yönelik tutum hem robotik restoranlarl kullanma niyetinin hem de robotik restoranlarl kullanmak için daha fazla ödeme yapma isteğinin olumlu ve önemli bir yordayıcısıdır. Çalışmanın sonunda sınırlılıklar çerçevesinde önerilerde bulunulmuştur.
Makale Geçmişi:

Iletilen Tarih:

22 Ekim 2021

Kabul Tarihi:

23 Aralik 2021

Jel Kodları:

M30, M31

Anahtar Kelimeler:

Robot Garsonlar,

Robotik Restoranlar,

Davranışsal Niyetler

Önerilen Alıntı: Çelik, Z. \& Aydın, İ. (2022). Restoranlarda Robot Garsonlar Kullanmanın Tüketicilerin Davranışsal Niyetlerine Etkisi. Cumhuriyet Üniversitesi İktisadi ve İdari Bilimler Dergisi, 23(1), 317-336.

1 Arş. Gör. Dr., Van Yüzüncü Y1l Üniversitesi, Erciş İşletme Fakültesi, İşletme Bölümü, zubeyircelik@yyu.edu.tr. ORCID ID: 0000-0003-1692-9378

2 Dr. Öğr. Üyesi, Van Yüzüncü Yıl Üniversitesi, Erciş İşletme Fakültesi, İşletme Bölümü, ibrahimaydin@yyu.edu.tr, ORCID ID: 0000-0002-0720-364X 
Zübeyir ÇELIKK \& İbrahim AYDIN, 2022 Cilt: 23, Sayı: 1, ss. 317-336.

\section{GİRİ̧̧}

Hizmet sektöründe servis robotlarının kullanımı giderek yaygınlaşmaktadır. Amerika Birleşik Devletleri, Türkiye, Güney Kore, Japonya, İngiltere, Çin, Hindistan, Birleşik Arap Emirlikleri ve İskoçya gibi birçok ülkede hizmet veren bazı restoranlarda servis robotları (şef robotlar, garson robotlar vesaire) kullanılmaktadır (Hazarhun ve Y1lmaz, 2020; Cha, 2020; Hwang vd., 2020a; Jang ve Lee, 2020; Mishra vd., 2018). Müşterilerine hizmet sağlamak için robot teknolojisini kullanan bir restorana robotik restoran denmektedir (Hwang vd., 2020a). Servis robotlarının hizmet sektöründe yaygınlaşması ile bu robotlar bazı araştırmacıların ilgisini çekmiş ve bu nedenle pazarlama araştırmalarına konu olmuştur (Ivanov vd., 2018). Yapılan çalışmalarda robotik restoranlar bağlamında müşterilerin tutum ve niyetleri, servis robotlarının özellikleri (Jang ve Lee, 2020), robotik restoranların genel imajı (Kim vd., 2021), motive olmuş tüketici yenilikçiliği faktörleri (Cha, 2020; Hwang vd., 2020b; Kim vd., 2021; Kwak vd., 2021; Sung ve Jeon, 2020), algilanan zevk (Cha, 2020; Sung ve Jeon, 2020), algılanan değer (Kwak vd., 2021), etkileşim (Lee vd., 2018; Sung ve Jeon, 2020), çıktı kalitesi (Lee vd., 2018), algılanan fayda, algılanan kullanım kolaylığ1 (Lee vd., 2018; Seo ve Lee, 2021; Sung ve Jeon, 2020), müşteri tatmini (Seo ve Lee, 2021), algilanan güven (Cha, 2020; Lee vd., 2018; Seo ve Lee, 2021), algilanan risk (Cha, 2020; Hwang vd., 2021; Seo ve Lee, 2021; Sung ve Jeon, 2020) ve ilgisizlik (Cha, 2020) ile ilişkili olarak incelenmiştir. Bu çalışma, ilgili literatürdeki çalışmalardan farklı olarak, restoranlarda robot garson kullanmanın tüketicilerin davranışsal niyetleri (kullanma niyeti ve daha fazla ödeme isteği) üzerindeki etkisini algılanan yenilikçilik, algılanan değer, algılanan zevk, çekicilik ve tutum faktörleri ile ilişkili olarak incelemektedir. Çalışmanın önceki çalışmalardan bir diğer farkı, robot garson kullanan restoranlara karşı tüketicilerin davranışsal niyetleri robot garsonlar, cinsiyet ve jenerasyonlar kontrol değişkenleri açısından anlamlı bir şekilde farklılaşıp farklılaşmadığını incelemesidir. Çalışmanın bu özgün yönleriyle literatüre ve iş dünyasına önemli katkılarının olacağı beklenmektedir.

\section{LITTERATÜR İNCELEMESI}

\subsection{Robot Garsonlar}

Robot garsonlar, robotik restoranlar gibi yeni restoran modellerinde müşterileri karş1layan, yardımcı olan ve hizmet veren yıkıcı (kendisinden önceki robot garson teknolojisinin yerini çok hızlı bir şekilde alan) bir teknolojidir (Kim vd., 2021). Basit bir ifadeyle robot garsonları yapay zekâ ile desteklenen akıllı fiziksel cihazlar olarak tanımlamak mümkündür (Ivanov vd., 2017). Robot garsonlar, insan garsonlardan çok farklı olmalarına rağmen, müşteriler robot garsonları işletmenin temsilcileri olarak görmektedir (Ho vd., 2020). Robot garsonlar, mutfakta çalışan robotik şeflerden farklı olarak müşterilerle yüz yüze iletişim kuran ve hizmet sunan genellikle sosyal niteliğe sahip servis robotlardır (Zhu ve Chang, 2020). Geçmişte restorandaki müşterilerin siparişleri insan garsonlar tarafından alınıp, yemeklerin servis ve sunumlarında robot garsonlar hizmet sunabiliyordu (Mishra vd., 2018). Günümüzde ise robot garsonların, restoranlarda kendi başlarına gezinme, müşterilerle konuşma ve menüyü açıklama, tepsi taşıma ve yemek sunma gibi yetenekleri vardır (Hwang vd., 2020a).

\subsection{Davranışsal Niyet}

Restoranlarda kullanılan robot garsonlar, müşterilerin siparişlerini yerine getirirken, bu robot garsonların potansiyel müşterilerin dikkatini çekebildiğini ve müşteriyi restorana çekme potansiyeline sahip olduğunu söylemek mümkündür. Zira, robot garsonların restoran müşteri algısı 


\section{RESTORANLARDA ROBOT GARSONLAR KULLANMANIN TÜKETICILERIN DAVRANISSSAL NIYYTLERINE ETKISSI}

ve davranışı üzerindeki etkisi, yakın zamanda yapılan birçok çalışma tarafından desteklenmiştir (Cha, 2020; Kwak vd., 2021). Tüketicilerin robotik restoranları tercih etme niyetleri olduğu bilinmektedir (Hwang vd., 2020a, 2020b). Bununla birlikte, pazarlama literatüründe daha önce yapılan çalışmaların sonuçlarına göre; cinsiyet açısından tüketicilerin, alışveriş deneyiminin zenginleştirilmesinde kullanılan bu tür yapay zekâ destekli teknolojiklere yönelik davranışsal niyetlerinde (Kim ve Forsythe, 2008) ve jenerasyonlar açısından tüketicilerin, bu tür teknolojileri kullanma süreçlerinde (Köse ve Yengin, 2018) anlamlı bir farklılık yoktur. Bu teorik arka plan dikkate alınarak $\mathrm{H}_{1 \mathrm{a}}, \mathrm{H}_{1 \mathrm{~b}}$ ve $\mathrm{H}_{1 \mathrm{c}}$ hipotezleri geliştirilmiştir.

$\mathrm{H}_{1 \mathrm{a}}$ : Robot garsonlar, tüketicilerin robotik restoranları kullanma niyetleri üzerinde olumlu ve anlamlı bir etkiye sahiptir.

$\mathrm{H}_{1 \mathrm{~b}}$ : Tüketicilerin robotik restoranları kullanma niyetlerinde cinsiyetler arasında anlamlı bir farklilik yoktur.

$\mathrm{H}_{1 \mathrm{c}}$ : Tüketicilerin robotik restoranları kullanma niyetlerinde jenerasyonlar arasında anlamlı bir farkl1lık yoktur.

\subsection{Algılanan Yenilikçilik}

Algılanan yenilikçilik, müşterinin yeni ve farklı olanı arama arzusuna göre; yemek, ortam/atmosfer ve hizmet gibi restoran deneyiminin temel niteliklerini yenilik olarak algılamasıdır (Jin vd., 2015). Robotik hizmetler, hizmet sektöründeki tüketici deneyimlerini iyileştirmek için yenilikçi bir teknolojidir (Zhong vd., 2020). Hem hedonik hem de sosyal olarak motive olmuş tüketici yenilikçiliği, robotik restoran kullanmaya yönelik tutum üzerinde etkilidir (Cha, 2020). Benzer şekilde, robotik restoranları (veya robot garsonları) kullanmanın algılanan yenilikçiliği, tüketicilerin robotik restoranları kullanmaya yönelik tutumlarında önemli bir belirleyicidir (Hwang vd., 2020b; Sung ve Jeon, 2020). Bu doğrultuda $\mathrm{H}_{2}$ hipotezi geliştirilmiştir.

$\mathrm{H}_{2}$ : Robotik restoranları kullanmanın algılanan yenilikçiliği, robotik restoranları kullanmaya yönelik tüketici tutumu üzerinde olumlu ve anlamlı bir etkiye sahiptir.

\subsection{Algılanan Değer}

Her şeyden önce robotlar mükemmel değillerdir ve hizmet hatası olduğunda insanlar robotları suçlayabilmektedir (Leo ve Huh, 2020). Ancak, tüketici, robot garsonların yemek sunumunu hatasız bir şekilde yönetebileceğini bilmelidir (Hwang vd., 2020b). Restoran hizmetlerinde kullanılan robot garsonların hizmet sunma yeterlilikleri konusuna yönelik yapılan deneylerde görüleceği üzere robot garsonların becerilerini geliştirmek ve böylece verimliliklerini artırmak mümkündür (Wan vd., 2020). Bir robot garson, restoran otomasyon sisteminin bir parças1 olarak, sipariş verme ve mutfaktan müşteri masasına yiyecek servisi konusunda iyi performans gösterebilmektedir (Asif vd., 2015). Robot garsonları kullanmanın algılanan değeri, tüketicilerin robotik restoranları kullanmaya yönelik tutumlarını etkilemektedir (Kwak vd., 2021). Bu teorik arka plana dayandırılarak $\mathrm{H}_{3}$ hipotezi geliştirilmiştir.

$\mathrm{H}_{3}$ : Robot garsonları kullanmanın algılanan değeri, robotik restoranları kullanmaya yönelik tüketici tutumu üzerinde olumlu ve anlamlı bir etkiye sahiptir.

\subsection{Algilanan Zevk}

Teknoloji merkezli zevk, web siteleri gibi bilgi teknolojilerinin hedonik özellikleri ile ilgilidir (Richard ve Chebat, 2016). Hedonik motivasyon, müşterilerin yapay zekâ destekli robotik cihazların kullanımına ilişkin değerlendirmelerini etkileyen önemli bir öncüldür (Lin vd., 2020). 
Zübeyir ÇELIKK \& İbrahim AYDIN, 2022 Cilt: 23, Sayı: 1, ss. 317-336.

Robot garsonların, dış görünüşleri ve sesleri gibi duygusal yönlere hitap eden özellikler tüketicilerin hedonik duygularını harekete geçirebilmektedir (Cha, 2020). Bu nedenle tüketiciler robot garsonlarla etkileşim kurmayı ve robot garsonlardan hizmet almayı unutulmaz, eğlenceli ve heyecan verici bir deneyim olarak görmektedir (Ivanov vd., 2018). Robot garsonları kullanmanın algılanan zevki, tüketicilerin robotik restoranları kullanmaya yönelik tutumlarının önemli bir belirleyicisidir (Sung ve Jeon, 2020). Bu bağlamda $\mathrm{H}_{4}$ hipotezi geliştirilmiştir.

$\mathrm{H}_{4}$ : Robot garsonları kullanmanın algılanan zevki, robotik restoranları kullanmaya yönelik tüketici tutumu üzerinde olumlu ve anlamlı bir etkiye sahiptir.

\section{6. Çekicilik}

Restoranlarda hizmet sunumu için yenilikçi bir fikir olduğu düşünülen yapay zekâ destekli yeni nesil robot garsonları kullanmak, çok fazla ilgi ve tüketici çekebilir (Ivanov vd., 2017). Bir robot, sosyal (hoş, eğlenceli ve sempatik) ve estetik (fiziksel özellikler ve yüz) açıdan tüketiciye çekici gelebilmektedir (Cha, 2020; Van Doorn vd., 2017). Hizmet sektöründe bir robot hizmetinin çekiciliği, zevki ve tercihi açısından tüketici algısı üzerinde etkilidir (Zhong vd., 2020). Ulaşım hizmetlerinde kullanılan yapay zekâ destekli robotların çekiciliği ile sürdürülebilir tutum arasında anlamlı bir ilişki vardır (Miskolczi vd., 2021). Bu ilişkiye dayalı olarak $\mathrm{H}_{5}$ hipotezi geliştirilmiştir.

$\mathrm{H}_{5}$ : Robot garsonları kullanmanın çekiciliği, robotik restoranları kullanmaya yönelik tüketici tutumu üzerinde olumlu ve anlamlı bir etkiye sahiptir.

\subsection{Tutum}

Tutum, bir kişinin belirli bir davranışı olumlu veya olumsuz herhangi bir dereceye kadar değerlendirmesidir (Ajzen, 1991). Tutum, teknolojik bir yeniliği kullanma niyetinin temel belirleyicisidir (Song vd., 2021). Buna göre; tüketici bir robot garson hizmetini veya robotik bir restoran kullanma niyetinden önce bir dereceye kadar olumlu veya olumsuz tutuma sahip olabilir. Hizmet endüstrisinde, tüketicinin servis robotlarına (şef garsonlar, robot garsonlar vesaire) yönelik kişisel tutumları, servis robotlarını kullanma niyetini etkilemektedir (Cha, 2020). Diğer bir deyişle, tüketicinin robotik restoran kullanımına yönelik tutumu, robotik restoran kullanma niyetinin önemli bir belirleyicisidir (Hwang vd., 2020b; Hwang vd., 2021). Aynı zamanda, tüketicinin robotik restoranları kullanmaya yönelik tutumu, diğer karşılaştırılabilir hizmetlere kıyasla robotik restoranları kullanmak için daha fazla ödeme yapma isteği üzerinde etkilidir (Hwang vd., 2021). Mevcut literatürdeki ampirik temellere istinaden $\mathrm{H}_{6}$ ve $\mathrm{H}_{7}$ hipotezleri geliştirilmiştir.

$\mathrm{H}_{6}$ : Robotik restoranları kullanmaya yönelik tüketici tutumu, robotik restoranları kullanma niyeti üzerinde olumlu ve anlamlı bir etkiye sahiptir.

$\mathrm{H}_{7}$ : Robotik restoranları kullanmaya yönelik tüketici tutumu, robotik restoranları kullanmak için daha fazla ödeme isteği üzerinde olumlu ve anlamlı bir etkiye sahiptir.

\section{YÖNTEM}

\subsection{Araştırmanın Modeli/Hipotezleri}

Şekil 1, araştırma modelini göstermektedir. Aynı zamanda, Şekil 1'de araştırma hipotezlerini görmek mümkündür. 


\section{RESTORANLARDA ROBOT GARSONLAR KULLANMANIN TÜKETICILERIN DAVRANISSSAL NIYYTLERINE ETKISSI}

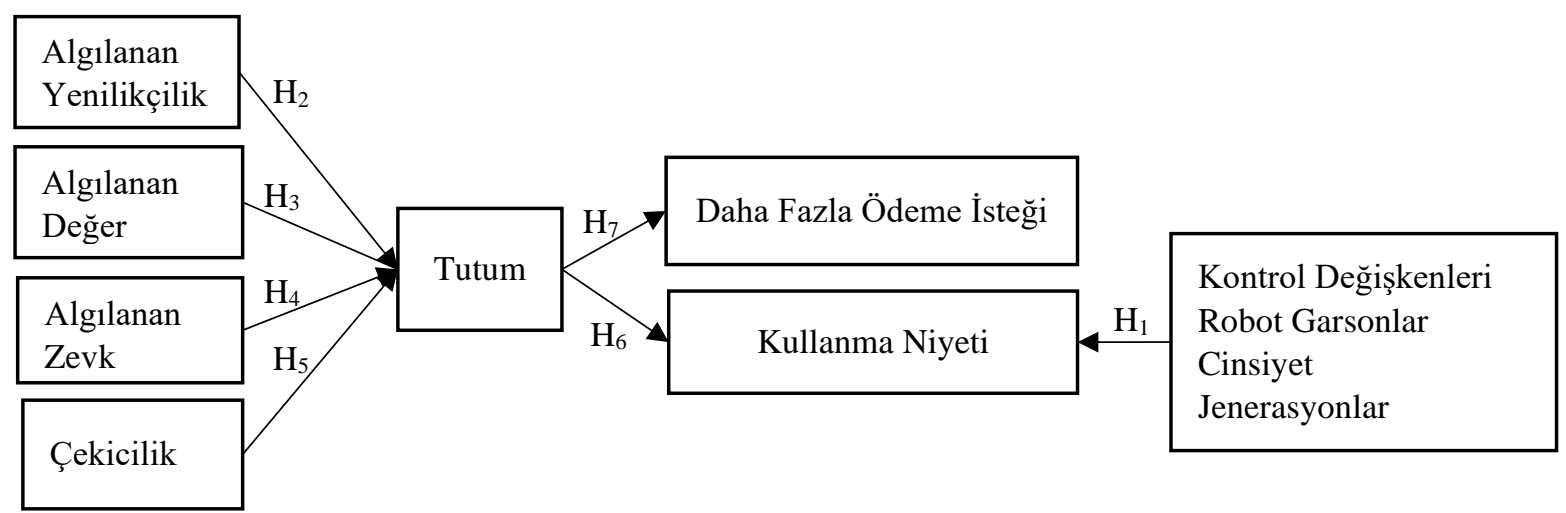

Şekil 1: Araştırma Modeli

\subsection{Evren, Örneklem ve Veri Toplama Aracı}

Türkiye İstatistik Kurumu 2021 yılı verilerine göre, Türkiye'nin 83 milyon 614 bin 362 kişilik nüfusu araştırmanın evrenini oluşturmaktadır. Diğer örnekleme teknikleri arasında kolayda örnekleme, evrenden veri toplamanın en kolay, en hızlı ve en ekonomik yoludur (Aaker vd., 2007). Zaman ve maliyet kısıtlarından dolayı kolayda örnekleme yöntemi ile evren içinden katılımcılara ulaşılmıştır. Deney ve online anket ile bu araştırma için veri toplanmıştır. Katılımcılar, online ankete katılım göstermeden önce bu çalışma için seçilen restoranlarda robot garsonların çalıştırılmasına yönelik online videoyu izlemişlerdir. Videonun içeriğinde restoran ismi ayrıca restoranda çalıştırılan robot garsonların marka isimlerine yer verilmemesine dikkat edilmiştir. Bu nedenle, mevcut araştırma belirli bir restoran veya marka ismine yönelik değildir. Diğer taraftan, deney ve anket yöntemi ile veri toplanacağından Van Yüzüncü Y1l Üniversitesi Sosyal ve Beşerî Bilimleri Yayın Etik Kurulu'na başvurulmuştur. 2021/15-08 sayılı ve 15.10.2021 tarihli onay belgesi alınmıştır.

Sonuç olarak, toplanan 388 anket arasında 3 anket hatalı olduğundan 385 anket değerlendirmeye alınmıştır. 385 kişilik örneklem büyüklüğü 24 ölçek maddesinin en az 10 katı büyüklüğünde olup 240 kişiden fazladır (Hair vd., 2009: s. 329). Aynı zamanda araştırma modelindeki değişken sayısına göre, 385 kişilik örneklem büyüklüğ̈̈ >15M (Stevens, 1996: s. 72) veya $>50+8 \mathrm{M}$ (Tabachnick ve Fidell, 2007: s. 123) olduğundan, minimum örneklem büyüklügü kriterlerini karşılamaktadır ( $\mathrm{M}=$ bağımsız değişken sayısı).

Araştırma evreninin (N=83 milyon 614 bin 362) büyüklüğü düşünüldüğünde, aşağıdaki formüle göre örneklem büyüklüğünün güven düzeyini hesaplamak mümkündür (Krejcie ve Morgan, 1970).

$$
\begin{aligned}
& \mathrm{n}=\frac{\mathrm{x}^{2} * \mathrm{~N} * \mathrm{P} *(1-\mathrm{P})}{\mathrm{d}^{2} *(\mathrm{~N}-1)+\mathrm{x}^{2} * \mathrm{P} *(1-\mathrm{P})} \\
& \mathrm{n}=\frac{3.841 * 83614362 * 0.5 *(1-0.5)}{(0.05)^{2} *(83614362-1)+3.841 * 0.5 *(1-0.5)} \\
& \mathrm{n}=384.098240158 \\
& \mathrm{n}: \text { İstenilen güven düzeyi için yeterli örneklem sayısı }
\end{aligned}
$$


Zübeyir ÇELIKK \& İbrahim AYDIN, 2022 Cilt: 23, Sayı: 1, ss. 317-336.

$\mathrm{x}^{2}$ : İstenen güven düzeyinde 1 serbestlik derecesi için ki-karenin tablo değeri

$\mathrm{N}$ : Evren

P: Popülasyon oranı (maksimum örneklem büyüklüğünü sağlayacağı için 0.5 olduğu varsayılmıştır).

d: 0.05 oranı olarak ifade edilen doğruluk derecesi.

83 milyon 614 bin 362 kişilik evren büyüklüğü ve kullanılan formüle göre, 385 kişiden oluşan çalışmanın örneklem büyüklüğü >384 olduğundan, araştırmanın örneklem büyüklüğü \%95 güven düzeyine sahiptir (Krejcie ve Morgan, 1970).

\section{3. Ölçekler ve Ölçek Soruları}

Daha önce yapılmış çalışmalardan yararlanılarak bu çalışmaya uyarlanan ölçek ve ölçek soruları kaynaklarıyla birlikte Tablo 1'de verilmiştir.

Tablo 1: Çalışma Ölçek Soruları ve Ölçek Sorularının Kaynağı

\begin{tabular}{|c|c|c|}
\hline \multicolumn{2}{|c|}{ Algılanan Yenilikçilik Ölçek Soruları } & Kaynak: Hwang vd. (2020b) \\
\hline Yenilikcilik1 & \multicolumn{2}{|l|}{ Robotik restoran benzersizdir. } \\
\hline Yenilikçilik2 & \multicolumn{2}{|l|}{ Robotik restoran yeni bir hizmettir. } \\
\hline Yenilikçilik3 & \multicolumn{2}{|l|}{ Robotik restoran özgün bir fikirdir. } \\
\hline \multicolumn{2}{|c|}{ Algılanan Değer Ölçek Soruları } & Kaynak: Kwak vd. (2021) \\
\hline Değer1 & \multicolumn{2}{|c|}{ Restoranda servis robotu, mükemmel bir performans sergilemektedir. } \\
\hline Değer2 & \multicolumn{2}{|c|}{ Restoranda servis robotunun kullanımı tatmin edici bir deneyim sunar. } \\
\hline Değer3 & \multicolumn{2}{|c|}{$\begin{array}{l}\text { Servis robotunu restoranlarda kullanmak, müşteriye yeterli derecede değer verildiği anlamına } \\
\text { gelmektedir. }\end{array}$} \\
\hline Değer4 & \multicolumn{2}{|c|}{ Restorandaki servis robotunun hizmet kalitesi mükemmeldir. } \\
\hline \multicolumn{2}{|c|}{ Algılanan Zevk Ölçek Soruları } & Kaynak: Cha (2020) \\
\hline Zevk1 & \multicolumn{2}{|c|}{ Müşterilerin servis robotu ile etkileşim kurması eğlenceli gözüküyor. } \\
\hline Zevk2 & \multicolumn{2}{|c|}{ Müşterilerin servis robotunu kullanarak hizmet alması eğlenceli gözüküyor. } \\
\hline Zevk3 & \multicolumn{2}{|c|}{ Müşterilerin servis robotunu kullanarak hizmet alması zevkli gözüküyor. } \\
\hline Zevk4 & \multicolumn{2}{|c|}{ Müșterilerin servis robotunu kullanarak sipariș vermesi eğlenceli gözüküyor. } \\
\hline \multicolumn{2}{|c|}{ Çekicilik Ölçek Soruları } & Kaynak: Cha (2020) \\
\hline Çekicilik1 & \multicolumn{2}{|l|}{ Servis robotu ilgi cekicidir. } \\
\hline Çekicilik2 & \multicolumn{2}{|l|}{ Servis robotu heyecan vericidir. } \\
\hline Çekicilik3 & \multicolumn{2}{|l|}{ Servis robotu havalıdır } \\
\hline Çekicilik4 & \multicolumn{2}{|l|}{ Servis robotu teknoloji harikasıdır. } \\
\hline \multicolumn{2}{|c|}{ Tutum Ölçek Soruları } & Kaynak: Hwang vd. (2020b) \\
\hline Tutum1 & \multicolumn{2}{|c|}{ Robotik restoran kullanımını hos karș1lyyorum. } \\
\hline Tutum2 & \multicolumn{2}{|c|}{ Robotik restoran kullanımını iyi karsıllyorum. } \\
\hline Tutum3 & \multicolumn{2}{|c|}{ Robotik restoran kullanımını olumlu karssılıyorum. } \\
\hline \multicolumn{2}{|c|}{ Daha Fazla Ödeme İsteği Ölccek Soruları } & Kaynak: Hwang vd. (2020b) \\
\hline Ödeme1 & \multicolumn{2}{|c|}{ Restoranda servis robot kullanımı için daha fazla ödeme yapabilirim. } \\
\hline Ödeme2 & \multicolumn{2}{|c|}{ Restoranda servis robot kullanımı için daha fazla ödemeyi kabul edebilirim. } \\
\hline Ödeme3 & \multicolumn{2}{|c|}{ Restoranda servis robot kullanımı icin ekstra ücret verebilirim. } \\
\hline \multicolumn{2}{|c|}{ Kullanma Niyeti Ölccek Soruları } & Kaynak: Hwang vd. (2020b) \\
\hline Niyet1 & \multicolumn{2}{|c|}{ Dışarıda yemek yerken robotik restoran kullanacağım. } \\
\hline Niyet2 & \multicolumn{2}{|c|}{ Dıșarıda yemek yerken robotik bir restoran kullanmaya hevesliyim. } \\
\hline Niyet3 & \multicolumn{2}{|c|}{ Dıșarıda yemek yerken muhtemelen robotik bir restoran kullanırım. } \\
\hline
\end{tabular}




\section{RESTORANLARDA ROBOT GARSONLAR KULLANMANIN TÜKETICILERİN DAVRANISSSAL NIYETLERINE ETKISI}

\subsection{Verilerin Analizi}

SPSS 25 paket programı elde edilen verileri analiz etmek için kullanılmıştır. Basit lineer regresyon analizi, bir bağımsız değişkenin bağımlı değişken üzerindeki etkisini test etmek için kullanılmıştır. Öte yandan, tek örneklem için t-testi, bağımsız örneklemler için t-testi ve bağımsız gruplar için tek yönlü varyans analizi (ANOVA) fark testleri için kullanılmıştır.

\section{BULGULAR}

Katılımcıların demografik özellikleri Tablo 2’de verilmiștir.

Tablo 2: Katılımcıların Demografik Özellikleri

\begin{tabular}{|c|c|c|c|}
\hline $\begin{array}{l}\text { Demografik } \\
\text { Özellikler }\end{array}$ & Grup & Frekans (f) & Yüzde (\%) \\
\hline \multirow{2}{*}{ Cinsiyet } & Kadın & 171 & 44,4 \\
\hline & Erkek & 214 & 55,6 \\
\hline \multicolumn{2}{|r|}{ Toplam } & 385 & 100 \\
\hline \multirow{4}{*}{ Yaş } & 9-25 yaş arası (1996-2012; $Z$ jenerasyon) & 132 & 34,3 \\
\hline & 26-40 yaş arası (1981-1995; Y jenerasyon) & 202 & 52,5 \\
\hline & 41-56 yaş arası (1965-1980; $X$ jenerasyon) & 42 & 10,9 \\
\hline & 57-75 yaș arası (1946-1964; Baby Boomer jenerasyon) & 9 & 2,3 \\
\hline \multicolumn{2}{|r|}{ Toplam } & 385 & 100 \\
\hline \multirow{4}{*}{ Eğitim Durumu } & İlkokul mezunu & 7 & 1,8 \\
\hline & Ortaokul mezunu & 13 & 3,4 \\
\hline & Lise mezunu & 92 & 23,9 \\
\hline & Üniversite mezunu & 273 & 70,9 \\
\hline \multicolumn{2}{|r|}{ Toplam } & 385 & 100 \\
\hline \multirow{4}{*}{ Aylık Gelir } & $0-2500 \mathrm{TL}$ aras 1 & 139 & 36,1 \\
\hline & $2501-5000 \mathrm{TL}$ aras1 & 90 & 23,4 \\
\hline & 5001-7500 TL aras1 & 71 & 18,4 \\
\hline & 7500 TL üstü & 85 & 22,1 \\
\hline \multicolumn{2}{|r|}{ Toplam } & 385 & 100 \\
\hline
\end{tabular}

Toplam katılımcı sayısı $(n=385 ; \% 100)$ arasında, erkek $(n=214 ; \% 55,6), 26-40$ yaş aralığındaki-Y jenerasyon $(n=202 ; \% 52,5)$, üniversite mezunu $(n=273 ; \% 70,9)$ ve 0-2500 TL arasında değişen aylık gelire sahip $(\mathrm{n}=139 ; \% 36,1)$ katılımcıların sayısı daha fazladır.

Faktör ve güvenilirlik analizi sonuçları Tablo 3 'te verilmiştir. 
Zübeyir ÇELIKK \& İbrahim AYDIN, 2022 Cilt: 23, Sayl: 1, ss. 317-336.

Tablo 3: Faktör ve Güvenilirlik Analizi Sonuçları

\begin{tabular}{|c|c|c|c|c|}
\hline Faktör İsmi & Faktör İfadeleri & Faktör Yükü & Açıklanan Varyans \% & Güvenilirlik \\
\hline \multirow{3}{*}{ Tutum } & Tutum2 & 910 & \multirow{3}{*}{60,839} & \multirow{3}{*}{,959 } \\
\hline & Tutum1 & 870 & & \\
\hline & Tutum3 &, 862 & & \\
\hline \multirow{3}{*}{$\begin{array}{l}\text { Daha Fazla Ödeme } \\
\text { İsteğ } i\end{array}$} & Ödeme3 & 987 & \multirow{3}{*}{9,695} & \multirow{3}{*}{ 958 } \\
\hline & Ödeme1 & 940 & & \\
\hline & Ödeme2 & ,938 & & \\
\hline \multirow{4}{*}{ Çekicilik } & Çekicilik2 &, 890 & \multirow{4}{*}{4,629} & \multirow{4}{*}{,919 } \\
\hline & Çekicilik3 & 865 & & \\
\hline & Çekicilik1 & ,856 & & \\
\hline & Çekicilik4 &, 772 & & \\
\hline \multirow{4}{*}{ Algılanan Zevk } & Zevk1 & ,933 & \multirow{4}{*}{4,491} & \multirow{4}{*}{,956 } \\
\hline & Zevk2 & ,929 & & \\
\hline & Zevk3 & ,876 & & \\
\hline & Zevk4 & ,720 & & \\
\hline \multirow{4}{*}{ Algılanan Değer } & Değer1 & ,913 & \multirow{4}{*}{3,388} & \multirow{4}{*}{,931 } \\
\hline & Değer4 & ,833 & & \\
\hline & Değer2 & ,785 & & \\
\hline & Değer3 & 699 & & \\
\hline \multirow{2}{*}{ Algılanan Yenilikçilik } & Yenilikçilik2 & ,888 & \multirow{2}{*}{2,635} & \multirow{2}{*}{,779 } \\
\hline & Yenilikçilik3 & ,874 & & \\
\hline \multirow{2}{*}{ Niyet } & Niyet3 &, 575 & \multirow{2}{*}{1,860} & \multirow{2}{*}{ 907 } \\
\hline & Niyet2 &, 572 & & \\
\hline \multicolumn{2}{|c|}{ Açıklanan Toplam Varyans \% } & \multicolumn{3}{|c|}{87,537} \\
\hline \multicolumn{3}{|c|}{ Kaiser-Meyer-Olkin (KMO) Örnekleme Yeterliliği Ölçütü } & \multicolumn{2}{|c|}{ 957 } \\
\hline \multirow{3}{*}{\multicolumn{3}{|c|}{ Bartlett's Küresellik Testi }} & Yaklaşık Ki-Kare & 9575,070 \\
\hline & & & df & 231 \\
\hline & & & p &, 000 \\
\hline
\end{tabular}

KMO değeri $\geq 0,50$ ve $p$ değeri $\leq 0,05$ olduğundan 385 katılımcıdan oluşan veri seti, faktör analizine uygulanmaya uygundur (Field, 2000). Faktör analizi sonucunda, faktör ifadeleri yüklerinin $\geq, 50$ ve açıklanan toplam varyansın $\geq \% 60$ olması beklenmelidir (Hair vd., 2009). Her bir faktör yükünün ,50 üzerinde ve açıklanan toplam varyansın $\% 87,537$ olduğu görülmektedir. Bunun yanı sıra, faktör boyutunun güvenilirlik değerinin $\geq, 70$ olması durumunda faktör boyutu güvenilir olarak kabul edilmelidir (Nunnally, 1978). Görüldüğü gibi her bir faktör boyutunun güvenilirlik değeri ,70 üzerindedir.

Tüm katılımcıların robotik restoranları kullanmaya yönelik davranışsal niyetlerinin anlaşılması amacıyla herhangi bir demografik fark gözetilmeden bütün veriler birlikte ele alınmıştır. Bunun için uygun istatistiki analiz olan tek örneklem t-testi uygulanmış elde edilen bulgular Tablo 4'te verilmiştir.

Tablo 4: Tek Örneklem t-Testi Sonuçları

\begin{tabular}{|c|c|c|c|c|c|c|c|}
\hline \multirow{2}{*}{ Bağımsız Değişken } & \multirow{2}{*}{ Bağımlı Değişken } & \multicolumn{5}{|c|}{ Test Value: $\mathbf{3}$} \\
\cline { 3 - 8 } & & Hipotez & $\overline{\mathbf{x}}$ & $\mathbf{S d}$ & $\mathbf{t}$ & $\mathbf{P}$ & Sonuç \\
\hline Robot Garsonlar Kullanımı & \multirow{2}{*}{ Kullanma Niyeti } & $\mathrm{H}_{1 \mathrm{a}}$ & 2,95 & 384 &,- 774 &, 440 & Ret \\
\hline
\end{tabular}




\section{RESTORANLARDA ROBOT GARSONLAR KULLANMANIN TÜKETICILERIN DAVRANIŞSAL NIYETLERINE ETKISI}

Robot garsonlar kullanımının, tüketicilerin robotik restoranları kullanma niyetleri üzerindeki etkisine yönelik anlamlı bir farklılaşmanın olmadığı sonucuna ulaşılmıştır $\left(\mathrm{t}_{384}=-774\right.$, $\mathrm{p}>0,05)$.

Bağımsız örneklemler t-testi sonuçları Tablo 5'te verilmiştir.

Tablo 5: Bağımsız Örneklemler t-Testi Sonuçları

\begin{tabular}{|c|c|c|c|c|c|c|c|c|}
\hline Grup & Hipotez & $\mathbf{n}$ & $\overline{\mathbf{x}}$ & Ss & Sd & $\mathbf{t}$ & $\mathbf{p}$ & Sonuç \\
\cline { 1 - 9 } Kadın & \multirow{2}{*}{$\mathrm{H}_{\mathrm{lb}}$} & 171 & 2,91 & 1,36 & \multirow{2}{*}{383} &,- 485 & \multirow{2}{*}{, 628} & \multirow{2}{*}{ Kabul } \\
\cline { 1 - 6 } & & 214 & 2,98 & 1,35 & & \\
\hline
\end{tabular}

Tüketicilerin robotik restoranları kullanma niyetlerinde cinsiyetler arasında anlamlı bir farkl1l1k yoktur $\left(\mathrm{t}_{383}=-, 485, \mathrm{p}>0,05\right)$.

Bağımsız gruplar için tek yönlü varyans (anova) analizi sonuçları Tablo 6'da verilmiştir.

Tablo 6: Bağımsız Gruplar İçin Tek Yönlü Varyans (Anova) Analizi Sonuçları

\begin{tabular}{|c|c|c|c|c|c|c|c|}
\hline $\begin{array}{c}\text { Varyansın } \\
\text { Kaynağı }\end{array}$ & Hipotez & $\begin{array}{c}\text { Kareler } \\
\text { Toplamı }\end{array}$ & Sd & $\begin{array}{c}\text { Kareler } \\
\text { Ortalaması }\end{array}$ & $\mathbf{F}$ & $\mathbf{p}$ & Sonuç \\
\hline Gruplararas1 & \multirow{3}{*}{$\mathrm{H}_{1 \mathrm{c}}$} & 2,114 & 2 & 1,057 & \multirow{3}{*}{, 573} & \multirow{3}{*}{,565 } & \multirow{3}{*}{ Kabul } \\
\hline Gruplar içi & & 688,426 & 373 & 1,846 & & & \\
\hline Toplam & & 690,540 & 375 & 2,903 & & & \\
\hline
\end{tabular}

Tüketicilerin robotik restoranları kullanma niyetlerinde $\mathrm{X}, \mathrm{Y}$ ve $\mathrm{Z}$ jenerasyonları arasında anlamlı bir farklılık yoktur $\left(\mathrm{F}_{(2,373)}=, 573 ; \mathrm{p}>0,05\right)$. 57-75 yaş arası (1946-1964; Baby Boomer jenerasyon) katılımcılar sadece 9 kişi olduğundan, bu yaş grubu (jenerasyon) analize dâhil edilmemiştir.

Basit lineer regresyon analizi sonuçları Tablo 7'de verilmiştir.

Tablo 7: Basit Lineer Regresyon Analizi Sonuçları

\begin{tabular}{|l|l|c|c|c|c|c|c|l|}
\hline $\begin{array}{l}\text { Bağımsız } \\
\text { Değişken }\end{array}$ & $\begin{array}{l}\text { Bağımlı } \\
\text { Değişken }\end{array}$ & Hipotez & $\mathbf{R}^{\mathbf{2}}$ & $\mathbf{F}$ & $\boldsymbol{\beta}$ & $\mathbf{t}$ & $\mathbf{p}$ & Sonuç \\
\hline $\begin{array}{l}\text { Algılanan } \\
\text { Yenilikçilik }\end{array}$ & Tutum & $\mathrm{H}_{2}$ &, 261 & 135,551 &, 511 & 11,643 &, 000 & Kabul \\
\hline $\begin{array}{l}\text { Alğlanan } \\
\text { Değer }\end{array}$ & Tutum & $\mathrm{H}_{3}$ &, 567 & 502,231 &, 753 & 22,411 &, 000 & Kabul \\
\hline $\begin{array}{l}\text { Algılanan } \\
\text { Zevk }\end{array}$ & Tutum & $\mathrm{H}_{4}$ &, 528 & 428,868 &, 727 & 20,709 &, 000 & Kabul \\
\hline Çekicilik & Tutum & $\mathrm{H}_{5}$ &, 453 & 316,908 &, 673 & 17,802 &, 000 & Kabul \\
\hline Tutum & $\begin{array}{l}\text { Kullanma } \\
\text { Niyeti }\end{array}$ & $\mathrm{H}_{6}$ &, 652 & 716,866 &, 807 & 26,774 &, 000 & Kabul \\
\hline Tutum & $\begin{array}{l}\text { Daha Fazla } \\
\text { Ödeme İsteği }\end{array}$ & $\mathrm{H}_{7}$ &, 294 & 159,592 &, 542 & 12,633 &, 000 & Kabul \\
\hline
\end{tabular}


Zübeyir ÇELIKK \& İbrahim AYDIN, 2022 Cilt: 23, Sayı: 1, ss. 317-336.

Robotik restoranları kullanmanın algılanan yenilikçiliği $(\beta=, 511 ; p=, 000)$, robot garsonları kullanmanın algılanan değeri $(\beta=, 753 ; p=, 000)$, algılanan zevki $(\beta=, 727 ; p=, 000)$ ve çekiciliği $(\beta=, 673 ; p=, 000)$, robotik restoranları kullanmaya yönelik tutum üzerinde olumlu ve anlamlı bir etkiye sahiptir. Öte yandan, robotik restoranları kullanmaya yönelik tutumun robotik restoranları kullanma niyeti $(\beta=, 807 ; p=, 000)$ ve robotik restoranları kullanmak için daha fazla ödeme isteği $(\beta=, 542 ; p=, 000)$ üzerinde olumlu ve anlamlı bir etkisi vardır. 


\section{RESTORANLARDA ROBOT GARSONLAR KULLANMANIN TÜKETICILERIN DAVRANISSSAL NIYYTLERINE ETKISSI}

\section{TARTIŞMA VE SONUÇLAR}

Teknolojik gelişmelerin yansımasına bağlı olarak insan hayatındaki gelişimler ve değişimler firmalar açısından tüketicileri memnun edebilmek amacıyla farklı sektörlerde farklı uygulamaların gerçekleştirilmesine neden olmaktadır. Bu uygulamalardan biri de restoranlarda robot garsonların kullanılmasıdır. Her ne kadar kulağa hoş gelse ve özellikle çocuklar için eğlenceli gözükse de firmalar açısından beklentilerin karşılanamama riski vardır. Hizmet sektöründe müşterilerin sıcak ilgi beklentileri ve güler yüzlü çalışanlar görme istekleri olduğundan dolayı insanların karşısına çıkacak robotların insani duygulara sahip olmaması, bu robotların istenilen verimi sağlayamama riski bulunmaktadır.

Çalışmadan elde edilen sonuçlara göre robot garson kullanımının, tüketicilerin robotik restoranları tercih etme niyeti üzerinde olumlu ya da olumsuz bir farklılaşmaya neden olmadığ görülmüştür. Yeni ve eğlenceli teknolojiler genellikle tüketicilerin kullanma niyetini arttırır (Vaportzis vd., 2017). Bu durumun aksine çalışma sonuçlarında tüketicilerin robot garson kullanımının tüketicilerin robotik restoranları kullanma niyeti üzerinde olumlu bir etkisi görülmemiştir. Bunun nedeninin hizmet işletmelerinde müşterilerin hizmet edecek çalışanın kendilerine samimi, güler yüzlü ve arkadaşça davranması beklentilerinin (Lovelock ve Wright, 1999) robotlar tarafindan karşılanamamasından kaynaklı olduğu düşünülmektedir. Zira bir robot, insana ait özelliklerden olan samimi olma gibi duygulardan yoksundur. Bundan dolayı her ne kadar ilgi çekici gibi görünse de robot garson kullanımının, tüketicilerin robotik restoranları kullanma niyeti üzerinde olumlu bir etkiye neden olmadığı düşünülmektedir. Go vd. (2020) robotların yeterince iyi performans gösterememelerinin müşterileri tatmin etmeyen bir hizmete neden olabileceğini belirtmişlerdir. Çalışmada çıkan bu sonuç tüketicilerin robotlar tarafından tatmin edici bir hizmet performansı gösteremeyeceğine olan inançtan da kaynaklanmış olabilir. Fakat bu konuda daha kesin bilgilere ulaşılabilmesi bakımından robot garson kullanma niyetine yönelik (özellikle derinlemesine mülakat yöntemiyle) yapılacak başka araştırmaların yapılması gerektiği düşünülmektedir.

$\mathrm{Bu}$ çalışmadan elde edilen sonuca göre tüketicilerin robotik restoranları kullanma niyetlerinde kadınlar ve erkekler arasında herhangi bir farklılığa rastlanmamıştır. Bu sonuç tüketicilerin teknolojik cihazlara yönelik davranışsal niyetler bağlamında Kim ve Forsythe (2008)'nin çalışmasıyla benzerlik göstermektedir. Ayrıca bu çalışmada tüketicilerin robotik restoranları kullanma niyetlerinde farklı jenerasyonlar arasında da herhangi bir farklılığa rastlanmamıştır. Bu sonuç; Köse ve Yengin (2018) 'in teknolojik cihazları kullanma süreçlerinde elde ettikleri bulgularla paralellik göstermektedir. Robotik restoranları kullanmanın algılanan yenilikçiliğinin robotik restoranları kullanmaya yönelik tutum üzerinde olumlu ve anlamlı bir etkiye sahip olduğu sonucuna ulaşılmıştır. Bu sonuç; Hwang vd. (2020b) ve Sung ve Jeon (2020)'un sonuçları ile benzerlik göstermektedir. Buradan hareketle tüketicilerin yenilikleri kullanmaya olan meraklarından ötürü algılanan yenilikçiliğin robotik restoranları kullanmaya yönelik tutum üzerinde olumlu etkilere neden olduğu yargısına varılabilir. Diğer bir sonuca göre, robot garsonları kullanmanın algılanan değerinin robotik restoranları kullanmaya yönelik tutum üzerinde olumlu ve anlamlı bir etkisi vardır. Bu sonuç; Kwak ve diğerleri (2021)'nin çalışmasında elde ettiği sonuç ile örtüşmektedir. Dahas bu çalışmada robot garsonları kullanmanın algılanan zevkinin robotik restoranları kullanmaya yönelik tutum üzerinde olumlu ve anlamlı bir etkiye sahip olduğu sonucuna ulaşılmıştır. Bu sonuç; Sung ve Jeon (2020) 'un çalışmasında elde ettiği sonuçla paralellik göstermektedir. Günümüz dünyasının hedonik amaçlarla hizmet satın alan tüketicilerinin, robot garson kullanımı için algıladıkları zevkin robotik restoranları kullanmalarına 
Zübeyir ÇELIKK \& İbrahim AYDIN, 2022 Cilt: 23, Sayı: 1, ss. 317-336.

yönelik tutumları üzerinde olumlu bir etkisinin bulunması şaşırtıcı olmamıştır. Bu çalışmada robot garsonları kullanmanın çekiciliği robotik restoranları kullanmaya yönelik tutum üzerinde olumlu ve anlamlı bir etkiye sahip olduğu görülmüştür. Bu sonuç; Zhong ve diğerleri (2020)'nin gerçekleştirdiği çalışmada robot tarafından verilen hizmetin çekiciliğinin, tüketici tercihi açısından etkili olduğunu bulduğu sonuç bağlamında benzerlik göstermektedir. Robotların eğlenceli, heyecan verici, şaşırtıcı olması (Yazıcı Ayyıldız ve Eroğlu, 2021), teknolojik görünmesi, çoğu tüketici için deneyimlenmemiş bir yenilik olması gibi nedenlerden dolayı tüketicilerin bu robotları çekici görmesinin, bu robotları kullanmaya yönelik tutumları üzerinde olumlu etkiye neden olduğu düşünülmektedir. $\mathrm{Bu}$ çalışmada robotik restoranları kullanmaya yönelik tutumun, robotik restoranları kullanma niyeti üzerinde olumlu ve anlamlı bir etkisi olduğu görülmüştür. Çalışmanın bu sonucu; Hwang ve diğerleri (2020b) ve Hwang ve diğerleri (2021)'nin çalışmalarında elde ettikleri bulgularla örtüşmektedir. Diğer bir sonuca göre; yine robotik restoranları kullanmaya yönelik tutumun, robotik restoranları kullanmak için daha fazla ödeme isteği üzerinde olumlu ve anlamlı bir etkisi olduğu bulunmuştur. Bu sonuç; Hwang ve diğerleri (2021)'nin elde ettiği sonuç ile benzerlik göstermektedir. 


\section{RESTORANLARDA ROBOT GARSONLAR KULLANMANIN TÜKETICILERİN DAVRANIŞSAL NIYETLERINE ETKISI}

\section{KISITLAMALAR VE ÖNERİLER}

Çalışmanın amaçlarından biri tüketicilerde robot garsonların kullanılma niyetini anlamaktır. Elde edilen sonuç tüketicilerin robot garsonları kullanma niyetinin olmadığı yönündedir. Böyle bir sonucun elde edilmesinin altında yatan nedenleri araştırmaya yönelik gerçekleştirilecek nitel bir araştırmayla tüketicilerin robot garsonları kullanma niyetlerinin olmamasına ilişkin nedenler anlaşılabilir. Elde edilecek sonuçlara göre ilgili firmalar tarafından gerekli faaliyetler gerçekleştirilebilir. Eğer tüketicilerin robot garsonların performansları hakkında endişeleri varsa bu endişelerin giderilmesi adına ilgili firmalar robot garsonların niteliklerinin reklam, pazarlama halkla ilişkiler gibi iletişim yollarıyla tüketiciyi bilgilendirme yoluna gidebilir. Eğer tüketiciler endişelerinde haklıysa buna göre robot garsonların özelliklerinin geliştirilmesi, iyileştirilmesi yoluna gidilebilir.

Her ne kadar robot garsonlar bazı ülkelerde ve Türkiye'de kullanılmaya başlanmışsa da çok az sayıda insan robot garsonların hizmetlerini deneyimlemiştir. Çalışmada video gösterilmesi katılımcıların robot garson hizmetlerini anlamada oldukça önemli olsa da gerçekleşen bir deneyimin olmaması bir kısıt olarak görülebilir. İleride robot garsonların yaygınlaşmasıyla beraber bu hizmetleri deneyimleyen tüketiciler üzerinde benzer çalışmalar gerçekleştirilebilir. Zira robot garsonlardan bire bir hizmet alan tüketicilerin tutumlarında farkl1lıklar olabilir.

Çalışmada algılanan zevk, algılanan yenilikçilik, algılanan değer, çekicilik ve demografik değişkenlerden cinsiyet ve jenerasyon değişkenleri ele alınmıştır. Gelecekte yapılacak çalışmalarda algılanan risk, eğitim gibi farklı değişkenlerin ele alındığı çalışmalar yapılabilir. 
Zübeyir ÇELIKK \& İbrahim AYDIN, 2022 Cilt: 23, Sayı: 1, ss. 317-336.

\section{KAYNAKÇA}

Aaker, D. A., Kumar,V. \& Day, G. S. (2007). Marketing Research, 9, John Wiley \& Sons, Danvers.

Ajzen, I. (1991). The Theory of Planned Behavior. Organizational Behavior and Human Decision Processes, 50(2), 179-211.

Asif, M., Sabeel, M. \& Mujeeb-ur Rahman, K. Z. (2015). Waiter Robot-Solution to Restaurant Automation. in Proceedings of the 1st Student Multi Disciplinary Research Conference (MDSRC), At Wah, Pakistan, November, 14-15.

Cha, S. S. (2020). Customers' Intention to Use Robot-Serviced Restaurants in Korea: Relationship of Coolness and MCI Factors. International Journal of Contemporary Hospitality Management, 32(9), 2947-2968.

Field, A. (2000). Discovering Statistics Using SPSS for Windows. London: Sage Publications.

Go, H., Kang, M. \& Suh, S. C. (2020). Machine Learning of Robots in Tourism and Hospitality: Interactive Technology Acceptance Model (iTAM)-Cutting Edge. Tourism Review, 75(4), 625-636.

Hair, J. F., Jr., Black, William C., Babin, B. J. \& Anderson, R. E. (2009). Multivariate Data Analysis, 7. Upper Saddle River, NJ: Prentice Hall.

Hazarhun, E. \& Yılmaz, Ö. D. (2020). Restoranlarda Dijital Dönüşüm: Touch Restoran Örneği. Gastroia: Journal of Gastronomy and Travel Research, 4(3), 384-399.

Ho, T. H., Tojib, D. \& Tsarenko, Y. (2020). Human Staff vs. Service Robot vs. Fellow Customer: Does It Matter Who Helps Your Customer Following a Service Failure Incident?. International Journal of Hospitality Management, 87, 102501.

Hwang, J., Kim, H., Kim, J. J. \& Kim, I. (2021). Investigation of Perceived Risks and Their Outcome Variables in the Context of Robotic Restaurants. Journal of Travel \& Tourism Marketing, 38(3), 263-281.

Hwang, J., Park, S. \& Kim, I. (2020). Understanding Motivated Consumer Innovativeness in the Context of a Robotic Restaurant: The Moderating Role of Product Knowledge. Journal of Hospitality and Tourism Management, 44, 272-282.

Hwang, J., Lee, K. W., Kim, D. \& Kim, I. (2020). Robotic Restaurant Marketing Strategies in the Era of the Fourth Industrial Revolution: Focusing on Perceived Innovativeness. Sustainability, 12(21), 9165.

Ivanov, S. H., Webster, C. \& Berezina, K. (2017). Adoption of Robots and Service Automation by Tourism and Hospitality Companies. Revista Turismo \& Desenvolvimento, 27(28), 15011517.

Ivanov, S., Webster, C. \& Garenko, A. (2018). Young Russian Adults' Attitudes Towards the Potential Use of Robots in Hotels. Technology in Society, 55, 24-32.

Jang, H. W. \& Lee, S. B. (2020). Serving Robots: Management and Applications for Restaurant Business Sustainability. Sustainability, 12(10), 3998.

Jin, N., Goh, B., Huffman, L. \& Yuan, J. J. (2015). Predictors and Outcomes of Perceived Image of Restaurant Innovativeness in Fine-Dining Restaurants. Journal of Hospitality Marketing \& Management, 24(5), 457-485. 


\section{RESTORANLARDA ROBOT GARSONLAR KULLANMANIN TÜKETICILLERIN DAVRANISSAL NIYYETLERINE ETKISİ}

Kim, J. J., Choe, J. Y. (J). \& Hwang, J. (2021). Application of Consumer Innovativeness to the Context of Robotic Restaurants. International Journal of Contemporary Hospitality Management, 33(1), 224-242.

Kim, J. \& Forsythe, S. (2008). Adoption of Virtual Try-On Technology for Online Apparel Shopping. Journal of Interactive Marketing, 22(2), 45-59.

Köse, N. \& Yengin, D. (2018). Dijital Pazarlamadan Fijital Pazarlamaya Geçişe Örnek Olarak Artırılmış Gerçeklik ve Sanal Gerçeklik Uygulamalarının Pazarlama Üzerindeki Katkılarının İncelenmesi. İstanbul Aydın Üniversitesi Dergisi, 10(1), 77-111.

Krejcie, R. V. \& Morgan, D. W. (1970). Determining Sample Size for Research Activities. Educational and Psychological Measurement, 30, 607-610.

Kwak, M. K., Lee, J. \& Cha, S. S. (2021). Senior Consumer Motivations and Perceived Value of Robot Service Restaurants in Korea. Sustainability, 13(5), 2755.

Lee, W. H., Lin, C. W. \& Shih, K. H. (2018). A Technology Acceptance Model for the Perception of Restaurant Service Robots for Trust, Interactivity, and Output Quality. International Journal of Mobile Communications, 16(4), 361-376.

Leo, X. \& Huh, Y. E. (2020). Who Gets the Blame for Service Failures? Attribution of Responsibility Toward Robot Versus Human Service Providers and Service Firms. Computers in Human Behavior, 113, 106520.

Lin, H., Chi, O. H. \& Gursoy, D. (2020). Antecedents of Customers' Acceptance of Artificially Intelligent Robotic Device Use in Hospitality Services. Journal of Hospitality Marketing \& Management, 29(5), 530-549.

Lovelock, C. H. \& Wright, L. (1999). Principles of Service Marketing and Management. New Jersey: Prentice Hall.

Mishraa, N., Goyal, D. \& Sharma, A. D. (2018). Issues in Existing Robotic Service in Restaurants and Hotels. In Proceedings of 3rd International Conference on Internet of Things and Connected Technologies (ICIoTCT), April, 26-27.

Miskolczi, M., Jászberényi, M. \& Tóth, D. (2021). Technology-Enhanced Airport ServicesAttractiveness from the Travelers' Perspective. Sustainability, 13(2), 705.

Nunnally, J. C. (1978). Psychometric Theory. New York: McGraw-Hill. PewInternet.

Richard, M. O. \& Chebat, J. C. (2016). Modeling Online Consumer Behavior: Preeminence of Emotions and Moderating Influences of Need for Cognition and Optimal Stimulation Level. Journal of Business Research, 69(2), 541-553.

Seo, K. H. \& Lee, J. H. (2021). The Emergence of Service Robots at Restaurants: Integrating Trust, Perceived Risk, and Satisfaction. Sustainability, 13(8), 4431.

Song, H., Ruan, W. J. \& Jeon, Y. J. J. (2021). An Integrated Approach to the Purchase Decision Making Process of Food-Delivery Apps: Focusing on the TAM and AIDA Models. International Journal of Hospitality Management, 95, 102943.

Stevens, J. (1996). Applied Multivariate Statistics for the Social Sciences, 3. Mahwah, NJ: Lawrence Erlbaum. 
Zübeyir ÇELIKK \& İbrahim AYDIN, 2022 Cilt: 23, Sayl: 1, ss. 317-336.

Sung, H. J. \& Jeon, H. M. (2020). Untact: Customer's Acceptance Intention Toward Robot Barista in Coffee Shop. Sustainability, 12(20), 8598.

Tabachnick, B. G. \& Fidell, L. S. (2007). Using Multivariate Statistics, 5. Pearson Education:Boston.

Wan, A. Y. S., Soong, Y. D., Foo, E., Wong, W. L. E. \& Lau, W. S. M. (2020). Waiter Robots Conveying Drinks. Technologies, 8(3), 44.

Van Doorn, J., Mende, M., Noble, S. M., Hulland, J., Ostrom, A. L., Grewal, D. \& Petersen, J. A. (2017). Domo Arigato Mr. Roboto: Emergence of Automated Social Presence in Organizational Frontlines and Customers' Service Experiences. Journal of Service Research, 20(1), 43-58.

Vaportzis, E., Giatsi Clausen, M. \& Gow, A. J. (2017). Older Adults Perceptions of Technology and Barriers to Interacting with Tablet Computers: A Focus Group Study. Frontiers in Psychology, 8, 1-11.

Yazıcı Ayyıldız, A. \& Eroğlu, E. (2021). Restoranlarda Kullanılan Akıllı Teknolojiler ve Robot Restoranlar Hakkında Tripadvisor'da Yapılan Yorumların Değerlendirilmesi. Journal of Tourism and Gastronomy Studies, 9(2), 1102-1122

Zhong, L., Sun, S., Law, R. \& Zhang, X. (2020). Impact of Robot Hotel Service on Consumers' Purchase Intention: A Control Experiment. Asia Pacific Journal of Tourism Research, 25(7), 780-798.

Zhu, D. H. \& Chang, Y. P. (2020). Robot with Humanoid Hands Cooks Food Better? Effect of Robotic Chef Anthropomorphism on Food Quality Prediction. International Journal of Contemporary Hospitality Management, 32(3), 1367-1383. 


\section{RESTORANLARDA ROBOT GARSONLAR KULLANMANIN TÜKETICILLERIN DAVRANIŞSAL NIYYETLERINE ETKISI}

\section{EXTENDED ABSTRACT}

The use of service robots in the service industry is becoming more and more common. Service robots are used in some restaurants serving in many countries such as the United States, Turkey, South Korea, Japan, England, China, India, United Arab Emirates, and Scotland (Cha, 2020; Hwang et al., 2020a; Jang and Lee, 2020; Mishra et al., 2018). With the widespread use of service robots in the service sector, these robots have attracted the attention of some researchers and therefore have been the subject of marketing research (Ivanov et al., 2018). Unlike studies in the related literature, this study examines the effect of using robot waiters in restaurants on consumers' behavioural intentions (intention to use and willingness to pay more) to perceived innovativeness, perceived value, perceived enjoyment, attractiveness, and attitude factors. Another difference of the study from previous studies is that it examines whether consumers' intention to use robot waiters in restaurants differs significantly in terms of robot waiters, gender, and generations control variables. It is expected that the study will make significant contributions to the literature and business world with these unique aspects.

Due to time and cost constraints, the participants were reached from the population with the convenience sampling method. Data were collected for this research by experiment and online questionnaire. Before participating in the online survey, the participants watched the online video of the operation of robot waiters in the restaurants. In video content, attention was paid not to include the name of the restaurant and the brand names of the robot waiters employed in the restaurant. Therefore, the current research is not aimed at a specific restaurant or brand name. The sample of the study consists of 385 people. The study of Hwang et al. (2020b) was used for the scale questions of perceived innovativeness, attitude, willingness to pay more, intention to use. For the perceived value scale questions, the study of Kwak et al. (2021) was used. For the perceived enjoyment and attractiveness scale questions, the study of Cha (2020) was used. Simple linear regression analysis was used to test the effect of an independent variable on the dependent variable. On the other hand, t-test for one sample, t-test for independent samples, and one-way analysis of variance (ANOVA) for independent groups were used for difference tests.

The finding results of the research are as follows: It was concluded there was no significant difference in the effect of using robot waiters on consumers' intention to use robotic restaurants $\left(t_{384}=-774, p>0.05\right)$. There is no significant difference between genders in consumers' intention to use robotic restaurants $\left(\mathrm{t}_{383}=-.485, \mathrm{p}>0.05\right)$. There is no significant difference between $\mathrm{X}, \mathrm{Y}$, and $\mathrm{Z}$ generations in consumers' intention to use robotic restaurants $\left(\mathrm{F}_{(2,373)}=, 573 ; \mathrm{p}>0.05\right)$. Perceived innovativeness $(\beta=.511 ; p=.000)$ of using robotic restaurants, perceived value $(\beta=.753 ; p=.000)$, perceived enjoyment $(\beta=.727 ; p=.000)$, and attractiveness $(\beta=.673 ; p=.000)$ has a positive and significant effect on the attitude towards using robotic restaurants. On the other hand, attitude towards using robotic restaurants has a positive and significant effect on the intention to use robotic restaurants $(\beta=.807 ; \mathrm{p}=.000)$ and willingness to pay more for using robotic waiters $(\beta=.542$; $\mathrm{p}=.000)$

Depending on the reflection of technological developments, and changes in human life cause different practices in different sectors to satisfy consumers in terms of companies. One of these applications is the use of robot waiters in restaurants. Although it sounds good and looks fun, especially for children, there is a risk of not meeting expectations for companies. In the service sector, there is a risk of not being able to provide the desired efficiency due to the warm attention expectations of the customers, their desire to see friendly employees, and the without emotions robots that will meet people. According to the results obtained from the study, it was observed that 
Zübeyir ÇELIKK \& İbrahim AYDIN, 2022 Cilt: 23, Sayı: 1, ss. 317-336.

the use of robot waiters did not cause a positive or negative differentiation on consumers' intention to use robotic restaurants. It is also noticed that new and entertaining technologies generally increase the intention to use in consumers (Vaportzis et al., 2017). However, according to the results, the use of robot waiters by consumers did not have a positive effect on consumers' intention to use robotic restaurants. The reason is the expectations of the customers in service businesses that the employee to serve them will be sincere, smiling, and friendly (Lovelock \& Wright, 1999) but that expectation cannot be met by the robots. Because a robot is devoid of emotions. Therefore, it is thought that the use of robot waiters doesn't have a positive effect on consumers' intention to use robotic restaurants. Go et al., (2020) stated that the inability of robots to perform well enough may result in a service that does not satisfy customers. This result in our study may also be due to the belief of consumers that robots cannot provide a satisfactory service performance. In another result, no difference was found between men and women in consumers' intention to use robotic restaurants. This result is similar to the study of Kim and Forsythe (2008) in the context of consumers' behavioural intentions towards technological devices. In addition, no difference was found between different generations in the intention of consumers to use robotic restaurants. This result shows parallelism in the context of the results obtained by Köse and Yengin (2018) in the process of using technological devices. It was concluded the perceived innovativeness of using robotic restaurants has a positive and significant effect on the attitude towards using robotic restaurants. This result is in line with the results of Hwang et al., (2020b) and Sung and Jeon (2020). According to this result, it can be concluded the perceived innovativeness due to the curiosity of consumers to use innovations has positive effects on the attitude towards using robotic restaurants. It was concluded the perceived enjoyment of using robot waiters had a positive and significant effect on the attitude towards using robotic restaurants. This result is in parallel with the result obtained in the study of Sung and Jeon (2020). It is not surprising that consumers of today's world who purchase services for hedonic purposes, perceived enjoyment for using robot waiters have a positive effect on their attitudes towards using robotic restaurants. It has been concluded the attractiveness of using robot waiters has a positive and significant effect on the attitude towards using robotic restaurants. This result is similar in the context of Zhong et al.'s (2020) study, which found that the attractiveness of the service provided by the robot is effective in terms of consumer preference. It is thought that the fact that consumers see these robots as attractive due to reasons such as being fun, looking technological, and being an innovation that is not experienced by most consumers has a positive effect on their attitudes towards using these robots. It was concluded the attitude towards using robotic restaurants has a positive and significant effect on the intention to use robotic restaurants. This result is consistent with the results obtained by Hwang et al., (2020b) and Hwang et al. (2021). In another result, it was found that the attitude towards using robotic restaurants has a positive and significant effect on the willingness to pay more for using robot waiters. This result is in line with the result obtained by Hwang et al. (2021).

One of the aims of the study is to understand the intention of using robot waiters in consumers. The result is that consumers do not intend to use robot waiters. With a qualitative study to investigate the reasons behind such a result, the reasons for the consumers' lack of intention to use robot waiters can be understood. According to the results to be obtained, the necessary activities are carried out by the relevant companies. If the consumers have concerns about the performance of the robot waiters, to eliminate these concerns, the relevant companies can inform the consumer about the qualifications of the robot waiters by means of communication such as advertising, marketing, and public relations. If the consumers are right in their concerns, it is possible to develop and improve the characteristics of the waiters accordingly. Although robot waiters have started to 


\section{RESTORANLARDA ROBOT GARSONLAR KULLANMANIN TÜKETICILERIN DAVRANISSSAL NIYETLERINE ETKISSI}

be used in some countries and Turkey, very few people have experienced the services of robot waiters. Although showing the videos in the study is very important for the participants to understand the robot waiter services, the lack of experience in using the robot waiter in real life can be seen as a limitation. With the spread of robot waiters in the future, similar studies can be carried out on consumers who experience these services. Because there may be differences in the attitudes of consumers who receive one-on-one service from robot waiters. In the study, perceived enjoyment, perceived innovativeness, perceived value, attractiveness, gender, and generation variables were discussed. In the future studies, studies that deal with different variables such as perceived risk and education can be conducted. 